\title{
Changes of Synaptic Efficacy in the Medial Geniculate Nucleus as a Result of Auditory Classical Conditioning
}

\author{
Matthew D. McEchron, ${ }^{1}$ Edward J. Green, ${ }^{1}$ Ray W. Winters, ${ }^{1}$ Thomas G. Nolen, ${ }^{2}$ Neil Schneiderman, ${ }^{1}$ and \\ Philip M. McCabe ${ }^{1}$
}

Departments of ${ }^{1}$ Psychology and ${ }^{2}$ Biology, University of Miami, Coral Gables, Florida 33124

In this study we examined inputs to neurons in the medial subnucleus of the medial geniculate nucleus (mMG) for changes of synaptic efficacy associated with heart-rate conditioning to an auditory conditioned stimulus (CS). Conditioningrelated changes of synaptic efficacy were measured in awake animals by examining $\mathrm{mMG}$ single-unit responses evoked by stimulation of one of two areas that send auditory CS and nonauditory information monosynaptically to the $\mathrm{mMG}$, the brachium of the inferior colliculus $(\mathrm{B} \mid \mathrm{C})$ and the superior colliculus (SC). Synaptic efficacy was measured before, immediately after, and $1 \mathrm{hr}$ after one session of classical conditioning with a tone CS and a corneal airpuff unconditioned stimulus. To determine whether conditioning produced changes of synaptic efficacy on the auditory BIC inputs to $\mathrm{mMG}$ cells and not general changes of cellular excitability, analyses of synaptic efficacy were performed on the $\mathrm{mMG}$ units that exhibited shortlatency evoked responses ( $<3.5 \mathrm{msec})$ to both $\mathrm{BIC}$ and $\mathrm{SC}$ stimulation. Analyses revealed that the $\mathrm{BIC}$ but not the $\mathrm{SC}$ test stimulus-evoked unit activity from the same neurons exhibited the following changes immediately after conditioning: decreases in unit response latency, increases in unit response reliability, and increases in spike frequency. BIC-evoked unit responses after pseudoconditioning did not exhibit these changes in unit responding. These results suggest that the synapses carrying auditory CS information to $\mathrm{mMG}$ neurons increase in strength as the result of associative conditioning with an acoustic CS. Some of these changes of synaptic efficacy remained $1 \mathrm{hr}$ after training.

Key words: synaptic efficacy; medial geniculate; plasticity; classical conditioning; heart rate; rabbit
A major goal in the neurobiological study of learning is to localize sites of neuronal plasticity within the CNS and to describe the mechanisms of this plasticity. One model of learning that has been used effectively for studying these mechanisms is the classical conditioning of autonomic/behavioral responses through the pairing of acoustic conditioned stimuli (CS) and noxious unconditioned stimuli (US). Using this model, several CNS areas have been implicated as potential sites of plasticity [e.g., medial subnucleus of the medial geniculate nucleus (mMG), amygdala, and auditory cortex]. Of these regions the $\mathrm{mMG}$ is particularly interesting, because this may be one of the first loci of neuronal plasticity within the conditioning circuit. Learning-related changes in $\mathrm{mMG}$ could then influence neuronal changes in other CNS areas (Weinberger et al., 1990; McEchron et al., 1995).

Because of its polymodal organization, $\mathrm{mMG}$ receives convergent CS and US information during classical conditioning with acoustic CS. Cells in mMG respond electrophysiologically to both auditory CS and facial somatosensory US information (Love and Scott, 1969; Aitkin, 1973; McEchron et al., 1995). Furthermore, the $\mathrm{mMG}$ receives auditory CS inputs from the inferior colliculus (IC) via the brachium of the IC (BIC) (Moore and Goldberg, 1963, 1966; Kudo and Niimi, 1980a,b; Calford and Aitkin, 1983; LeDoux et al., 1987) and facial somatosensory US inputs from the spinal trigeminal complex (Lund and Webster, 1967; Jones and

\footnotetext{
Received July 3, 1995; revised Oct. 23, 1995; accepted Nov. 1, 1995.

This research was supported by NSF Grant IBN9222194 and NIH Grant HL07126. This work was presented by M.D.M. as partial fulfilment of the requirements for a PhD in behavioral neuroscience at the University of Miami. We thank Tim Webber and Ying Huang for their technical assistance.

Correspondence should be addressed to Philip M. McCabe, Department of Psychology, University of Miami, P.O. Box 248185, Coral Gables, FL 33124.

Copyright 1996 Society for Neuroscience $0270-6474 / 96 / 161273-11 \$ 05.00 / 0$
}

Burton, 1974; Erzurumlu and Killackey, 1980; Ring and Ganchrow, 1983; Peschanski, 1984; Iwata et al., 1992). Other areas such as the superior colliculus (SC) also project monosynaptically to $\mathrm{mMG}$ (Altman and Carpenter, 1961; Tarlov and Moore, 1966; Martin, 1969; Graham, 1977; Holstege and Collewijn, 1982).

Several lines of research have suggested that $\mathrm{mMG}$ plays an important role in classical conditioning with an acoustic CS. For instance, studies in lesioned mMG have shown that this area is essential for autonomic/behavioral conditioning with an acoustic CS (Jarrell et al., 1986; LeDoux et al., 1986; McCabe et al., 1993). In addition, electrophysiological studies have shown that $\mathrm{mMG}$ neuron responses to an auditory CS change as a function of conditioning (Gabriel et al., 1975; Supple and Kapp, 1989; Edeline and Weinberger, 1992; McEchron et al., 1995). Although this evidence suggests that neuronal plasticity may occur in $\mathrm{mMG}$, it docs not rule out the possibility that plasticity occurs in other CNS areas and is relayed to mMG. Gerren and Weinberger (1983) have provided evidence that plasticity can occur locally in $\mathrm{mMG}$ by showing that high-frequency stimulation of BIC produces longlasting electrophysiological changes in mMG. However, it is still unclear whether plasticity in $\mathrm{mMG}$ occurs as the result of associative learning, and it is also unclear whether plasticity occurs at auditory CS inputs to $\mathrm{mMG}$ cells. Therefore, the present study examined auditory and control inputs to $\mathrm{mMG}$ neurons for changes of synaptic efficacy associated with heart-rate (HR) conditioning to an acoustic CS. The efficacy of these synaptic inputs was tested by examining short-latency mMG unit responses evoked by electrical stimulation BIC and SC before, immediately after, and $1 \mathrm{hr}$ after conditioning. 


\section{MATERIALS AND METHODS}

Subjects. A total of 53 New Zealand albino rabbits of both sexes (2.5-3.5 $\mathrm{kg}$ ) were used in this investigation. All aninals were maintained on a 12 $\mathrm{hr}$ light/dark cycle with food and water provided ad libitum.

Surgery. All surgery was conducted under aseptic conditions. Animals were anesthetized with gaseous halothane $(2.0-3.0 \%$ in $100 \%$ oxygen, flow rate $500-600 \mathrm{cc} / \mathrm{min}$ ) and positioned in a Kopf stereotaxic frame. After a midline incision, cranium exposure, and trephining, animals were stereotaxically implanted with one stereotrode in the right $\mathrm{mMG}$, one stimulating electrode in the right BIC, and one stimulating electrode in the right $\mathrm{SC}$. Jeweler's screws twisted 1-2 mm into the skull were used as a reference and ground for the stereotrode. The tips of the stereotrode were placed in the vicinity of $\mathrm{mMG}$ units that responded to auditory-click stimuli. The tips of the stimulating electrodes were positioned so that low-current pulses ( $<250 \mu \mathrm{A}, 50 \mu \mathrm{sec})$ consistently evoked short-latency ( $<3.5 \mathrm{msec}$ from the offset of the pulse) unit responses in mMG. Dental cement was then used to secure the electrodes in place. All animals were allowed 2-3 di of recovery before any handling or testing.

Apparatus. Bipolar stimulating electrodes were constructed by mounting two Teflon-coated stainless steel wires (each wire, $110 \mu \mathrm{m}$ outside diameter) in a 23-gauge stainless steel tube. The wires were cut flush at the tips to allow $1 \mathrm{~mm}$ of the wires to protrude from the cannula. This produced an impedance of $100 \mathrm{k} \Omega$ at $1 \mathrm{kHz}$ for each wire. Biphasic, constant-current pulses ( $100 \mu \mathrm{sec} / \mathrm{phase}, 1 \mathrm{msec}$ interphase interval) were delivered through the stimulating electrodes by a stimulus isolator (model A365, World Precision Instruments, Sarasota, FL). A three-digit analog intensity setting on the stimulus isolator allowed individual pulse intensities to be reproduced accurately throughout the training session. The variability of the current intensity delivered by the stimulus isolator was tested throughout the investigation and had an SE of $<0.19 \mu \mathrm{A}$ at the range of intensities used in these experiments.

The stereotrode permitted concurrent recording of a number of single units across training (McNaughton et al., 1983). Each stereotrode was made by bonding two lacquer-coated tungsten wires (each wire, $20 \mu \mathrm{m}$ outside diameter) together with epoxylite to form two distinct recording channeis, $\mathrm{X}$ and $\mathrm{Y}$. The stereotrode wires were cut flush at the tip to produce a center-to-center spacing of $\sim 10-15 \mu \mathrm{m}$ and an impedance of $100-400 \mathrm{k} \Omega$ at $1 \mathrm{kHz}$ for each wire. The stereotrode was mounted in a 23 -gauge stainless steel cannula, and the tips were allowed to protrude 2 $\mathrm{mm}$ from the end of the cannula. The cannula was attached to a miniature chronic microdrive with threaded support posts. Rotation of the support posts allowed for small movements of the stereotrode on the day of recording.

$\Lambda$ nalog signals from channels $\mathrm{X}$ and $\mathrm{Y}$ of the stereotrode were fed through a Grass high impedance probe (model HIP5, Quincy, MA) situated near the animal. The analog signal from each channel was then amplified $20,000 \times$ by a Grass P511AC amplifier, which used a band-pass filter of $10-20 \mathrm{kHz}$ high frequency and $300 \mathrm{~Hz}$ low frequency. The amplified signals were then sampled at $32 \mathrm{kHz} /$ channel by a computer consisting of a $25 \mathrm{MHz} 80486 \mathrm{CPU}$ and a 12-bit, $150 \mathrm{kHz}$ analog-to-digital converter. Electrocardiographic (EKG) activity was recorded during conditioning for each animal using a Grass model 7 polygraph. EKG recording electrodes were stainless steel safety pins inserted subcutaneously in the chest and nape to form a lead II configuration. The EKG signal was amplified using a Grass model 7P5 AC preamplifier.

During training, each animal was positioned in a Plexiglas restrainer with an adjustable back and head stock that immobilized the head of the animal. The restrainer was secured within a ventilated, sound-altenualing chamber illuminated by two $6 \mathrm{~W}$ light bulbs. Background white noise $[60$ $\mathrm{dB}$ sound pressure level (SPL)] and the CS $(3350 \mathrm{~Hz}$ tone, $70 \mathrm{~dB}$ SPL, 2 sec duration) were provided through an $8 \Omega$ speaker positioned $20 \mathrm{~cm}$ anterior to the head of the subject. Before testing each animal, auditory stimuli were calibrated using an SPL meter positioned where the ears of the animal normally would be in the chamber. A $0.5 \mathrm{sec}$ puff of air delivered to the center of the right cornea served as the US. The air puff US was delivered through a 14-gauge blunt hypodermic tube perpendicular to the tangent plane of the globe of the eyeball. The tip of the hypodermic tube was positioned $1 \mathrm{~cm}$ from the cornea by a lightweight, flexible support fastened to the head of the animal by a Velcro strap that allowed full visibility from both eyes. Tailor hooks fastened to the Velcro strap pulled the eyelids apart to expose the cornea. A regulator attached to a tank of compressed nitrogen controlled the amount of pressure released by a $28 \mathrm{~V}$ Skinner valve in line between the tank and hypodermic tube. The air puff pressure $\left(15 \mathrm{~N} / \mathrm{cm}^{2}\right)$ was calibrated at the hypodermic tube using a sphygmomanometer-calibrated Gould (Cleveland, $\mathrm{OH}$ ) linear pressure transducer amplified by a Grass model 7P1 DC preamplifier.

The computer that sampled the neural data also controlled the delivery of all CS and US. An event flag was inserted automatically in the data stream for the onset and offset of each event to analyze stimulus-evoked neural activity.

Conditioning and stimulation procedures. Before behavioral testing, animals were acclimated to the experimental chamber for $30 \mathrm{~min}$. During this time, the stereotrode was moved ventrally by turning the posts of the microdrive to locate single $\mathrm{mMG}$ neurons that could be activated at a short latency $(<3.5 \mathrm{msec})$ by low-current electrical stimuli delivered to $\mathrm{BIC}$ and/or SC.

After acclimation, animals were given 30 habituation trials [intertrial interval $(\mathrm{ITI})=60 \pm 10 \mathrm{sec}$. On each habituation trial, the CS was presented without the US. After 30 trials, the bradycardiac response to the CS was no more than -7.5 beats/min. Measurements of HR were taken on the first and last 10 trials of habituation.

Immediately after habituation, animals were given test stimuli through each of the stimulating electrodes in BIC and SC (sites), whereas unit responses were recorded from $\mathrm{mMG}$. These test pulses served as probe stimuli to test for changes of synaptic efficacy. Figure $1 A$ shows a schematic representation of the sites of stimulation and the placement of the recording electrode in the $\mathrm{mMG}$. Single $\mathrm{mMG}$ unit responses cvoked by BIC stimulation were used to examine the efficacy of synapses that transmit auditory CS information. The $\mathrm{mMG}$ unit responses evoked by SC stimulation served as controls to examine the efficacy of synapses carrying nonauditory information to the same cells. Figure $1 B$ shows waveforms of a single $\mathrm{mMG}$ neuron evoked by both BIC and SC test stimuli. Three intensities were selected for each test stimulation site at the time of recording by carefully examining the evoked unit response activity on an oscilloscope. The lowest intensity for each site was selected as the amount of current that evoked short-latency $(<3.5 \mathrm{msec})$ unit responses $\sim 50 \%$ of the time (threshold). The next current intensity for each site evoked short-latency unit responses $\sim 1.0-1.5$ limes threshold. The highest intensity for each site was the amount of current $(<250 \mu \mathrm{A})$ that evoked unit activity 1.5-2.0 times threshold without artifact distortion. The stimulation procedure began by delivering 50 test stimuli at 2 sec intervals to one site at the lowest intensity. Then the other site was stimulated 50 times at its lowest intensity. This process was repeated at the second and third intensity for each site. The order with which the two sites were stimulated was counterbalanced across animals. This stimulation procedure took $\sim 10 \mathrm{~min}$. The procedure was repeated immediately after and $1 \mathrm{hr}$ after conditioning or pseudoconditioning. These three periods of test stimulation will be referred to as phases (pretraining, post-training, and 1 hr post-training).

Immediately after the pretraining phase of stimulation, the animals received one Pavlovian conditioning session (20) trials; ITI $=60 \pm 10 \mathrm{sec}$ ) or one pseudoconditioning session ( 38 trials; ITI $=30 \pm 10 \mathrm{sec}$ ). The conditioning session consisted of 18 trials in which the CS was paired with the US, and two CS test trials in which the CS was presented alone. During CS-US pairings, onset of the US occurred simultaneously with the offset of the CS. The CS test trials were presented every tenth trial to allow for measurements of HR without I IS artifact. A pseudoconditioning session was used to control for possible nonassociative changes in synaptic efficacy. During the pseudoconditioning session, 18 trials of the CS and 18 trials of the US were presented quasirandomly with the limitation that the same stimulus was presented on no more than two consecutive trials. The two CS test trials of the pseudoconditioning session were presented every twentieth trial. The total session time and the number of CS and US were the same for both the conditioning and the pseudoconditioning procedures.

Immediately after the last test trial of training, the post-training phase of stimulation was administered with the same intensities that were used in the pretraining phase. The final $1 \mathrm{hr}$ post-training phase of stimulation was administered $60 \mathrm{~min}$ after the last CS test trial of training, again using the same intensities. After the $1 \mathrm{hr}$ post-training phase of stimulation, animals received an additional CS test trial.

Antidromic collision tests. In a separate group of 10 animals, the monosynaptic latency of the BIC and SC projections to single $\mathrm{mMG}$ neurois was examined by measuring the latency of BIC and $\mathrm{SC}$ units evoked antidromically from $\mathrm{mMG}$. The latency of antidromically evoked unit responses was used as a reference to determine whether the orthodromic $\mathrm{mMG}$ unit responses evoked from $\mathrm{BIC}$ and $\mathrm{SC}$ during training were consistent with monosynaptic latencies. In these tests, animals were anesthetized and a bipolar stimulating electrode was lowered into the 


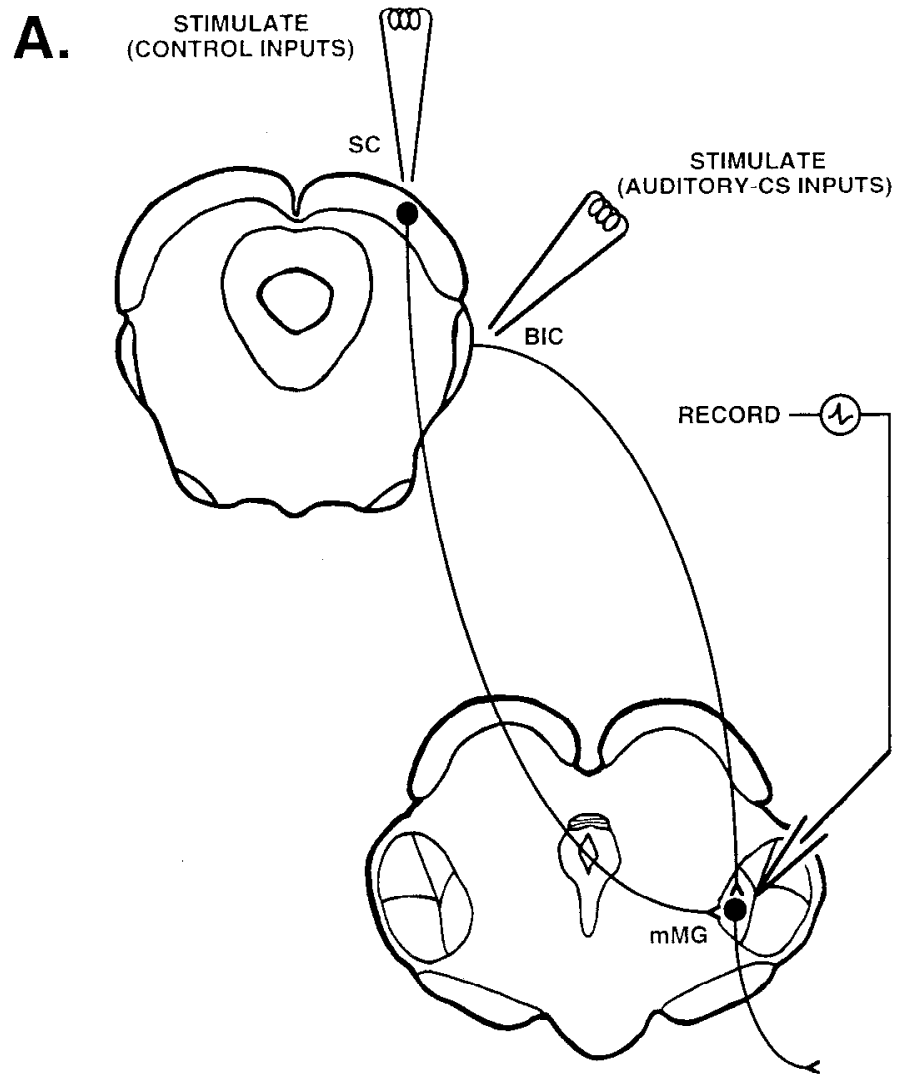

B. MMG UNIT
EVOKED FROM BIC

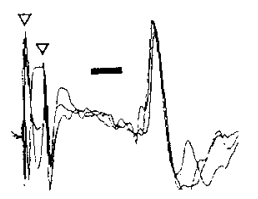

SAME MMG UNIT EVOKED FROM SC

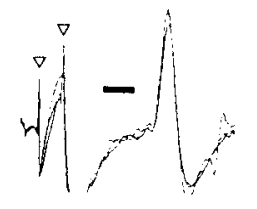

Figure 1. $A$, Schematic representation of the sites of stimulation and the placement of the recording electrode in the area of the $m M G$. Single $\mathrm{mMG}$ unit responses evoked by test stimulation of the $B I C$ were used to examine conditioning-induced changes in the efficacy of synapses that transmit auditory CS information. The same $\mathrm{mMG}$ neurons were activated by test stimuli delivered to the $S C$ to examine pathway-specific changes in unit responding. $B$, Three waveforms of an mMG neuron $120 \mu \mathrm{V}$ in amplitude (negative voltage upward) that was evoked by both $B I C$ (left) and $S C$ (right) test stimuli. Open inverted triangles indicate onset and offset of the biphasic test stimulus, and bars represents $1 \mathrm{msec}$. For this neuron, the test stimulus-evoked unit latency from stimulus offset was $3.0 \mathrm{mscc}$.

$\mathrm{mMG}$; a tungsten recording electrode was lowered into the BIC or SC. The recording electrode (Frederic Haer, Brunswick, ME) was insulated except for the tip, which was etched to $<1 \mu \mathrm{m}$ to produce an impedance of $11 \mathrm{M} \Omega$. The fine tip of the recording electrode was used to isolate individual neurons in SC and nerve fibers in BIC. Antidromic spikes were produced by stimulating in $\mathrm{mMG}$ and recording action potentials in $\mathrm{BIC}$ or SC. Evoked antidromic unit latency was measured from the offset of the electrical pulse.

A collision test also was performed to provide evidence that the BIC and SC units were generated antidromically. Collisions occurred between spontaneous spikes in $\mathrm{BIC}$ and $\mathrm{SC}$ and antidromic spikes generated clectrically in mMC. Spontaneous activity from BIC or SC was monitored with a Tektronics oscilloscope (Beaverton, OR). Spontaneous spikes triggered the constant-current stimulus isolator, which produced a uniphasic electrical pulse $(<200 \mu \mathrm{A}, 50 \mu \mathrm{sec})$ in $\mathrm{mMG}$. The electrical pulse at $\mathrm{mMG}$ produced an antidromic spike that was recorded in BIC or $\mathrm{SC}$ when the interval between the spontaneous spike and the electrical stimulus was greater than a critical delay for that particular antidromic spike. When the interval was less than the critical delay, however, an antidromic collision occurred, and the antidromic spike was not present in BIC or SC. The critical delay for a spike was estimated by adding the latency of the antidromic action potential to the refractory period of the axon. The axonal refractory period was estimated by determining the minimal interval between paired pulses ( $1.5 \times$ threshold intensity) that produced two antidromic spikes $100 \%$ of the time.

Histology. At the end of testing, a small lesion (100 $\mu \mathrm{A}$ anodal current, $25 \mathrm{sec}$ ) was made at the tips of the electrodes to verify the location of the recording and stimulating sites. All animals were then overdosed with sodium pentobarbital and perfused transcardially with $0.9 \%$ saline followed by $4 \%$ formalin. The brain was removed and soaked in a formalinsucrose solution for several days before sectioning. Frozen coronal sections $(40 \mu \mathrm{m})$ through the lesioned area were soaked in a $10 \%$ potassium ferrocyanide solution to locate the center of the stimulation and recording sites. Sections were then mounted on gelatin-coated slides and stained with Neutral Red. Sections were traced, and the recording and stimulating sites were plotted under a magnification of $10 \times$ and $40 \times$ using a Nikon microscope and drawing tube.

Single-unit and $H R$ analyses. Single-unit analog signals recorded from $\mathrm{mMG}$ were analyzed with the aid of Discovery software (DataWave Technologies, Longmont, $\mathrm{CO}$ ). Analog signals from each channel of the stereotrode ( $\mathrm{X}$ and $\mathrm{Y}$ ) were used to separate single units. If the signal from either channel exceeded the user-defined threshold set during the recording session, a $1 \mathrm{msec}$ epoch of data was collected from both channels. The software allowed for the separation neurons based on measurements of spike height and width obtained from the digitized signals from $\mathrm{X}$ and $\mathrm{Y}$. Spike separation was also verified visually with a software oscilloscope. Analyses were performed using only those neurons that could be reliably separated and tracked across the entire training session.

The $\mathrm{mMG}$ single-unit responses to $\mathrm{BIC}$ and $\mathrm{SC}$ test stimuli were used to measure learning-related changes of synaptic efficacy. Several measures of the test stimulus-evoked unit response served to indicate increases in synaptic efficacy: decreases in evoked single-unit latency, increases in the reliability of evoked single-unit discharge (increases in the percentage of time-locked unit responses to test stimulation), and increases in the evoked spike discharge frequency. Previous studies in the hippocampus and mMG have used similar measurements to indicate increases in synaptic efficacy (Bliss and Lomo, 1973; Andersen et al., 1980; Gerren and Weinberger, 1983). Each of these measures was calculated for each set of 50 test pulses at each intensity of each phase of training. The latency of all unit discharges was calculated using $0.1 \mathrm{msec}$ bins. The mean unit response latency was calculated using the latency of the first spike evoked within a $10 \mathrm{msec}$ period after the offset of each test stimulus. Unit discharges with a latency of $>10 \mathrm{msec}$ were not used in the latency calculations. The mean unit response latency of each set of 50 test stimuli was then used to determine whether the unit responses to each of these test stimuli was time-locked. A unit response to a test stimulus was time-locked if the first evoked spike occurred within $\pm 2.0 \mathrm{msec}$ of the mean response latency. Test stimulus-evoked spike frequency was measured by comparing the number of spikes in the first $10 \mathrm{msec}$ bin after pulse offset with the average of the five $10 \mathrm{msec}$ bins in the baseline period preceding stimulus onset. A standard score was then computed for the change in test stimulus-evoked spike frequency at each test stimulus intensity and phase of training, treating the baseline as sample variance. The baseline frequency of unit discharge was measured by counting the number of spikes fired by a neuron in the $1 \mathrm{sec}$ preceding the onset of a test stimulus.

Only the BIC and SC sites that evoked unit responses consistent with a monosynaptic projection were used in the analyses of test stimulation. This criterion was used to provide evidence that changes of synaptic efficacy occurred at the synaptic inputs to neurons in $\mathrm{mMG}$ and not in another structure outside of $\mathrm{mMG}$ via a polysynaptic connection. In this study, the latency of BIC and SC unit responses evoked antidromically from $\mathrm{mMG}$ were as much as $2.5 \mathrm{msec}$. This antidromic latency measurement, along with a short synaptic delay, suggests that orthodromic mMG units generated monosynaptically from BIC and SC may occur with a latency of as much as 3.5 msec. Thus, individual unit responses that were evoked at a short $(<3.5 \mathrm{msec})$ and fixed latency $(>70 \%$ of responses time-locked) before training were considered to be consistent with a monosynaptic projection. The test stimulation analyses were performed by grouping the intensities for each site of each neuron according to the percentage of time-locked evoked unit responses. This allowed neurons 
to be compared at similar levels of evoked unit discharge. The results suggest that sites could be grouped at only two of the three intensities because of the different levels of evoked responses of the multiple cells recorded from a single stereotrode. The two intensities used in the analyses were those that produced monosynaptically evoked responses $1.4-2.0$ times threshold and $0.8-1.4$ times threshold during the pretraining phase of stimulation.

The HR was computed by measuring successive five-beat R-R (EKG R-waves) intervals to the nearest $0.5 \mathrm{~mm}$ from the polygraph chart at a 25 $\mathrm{mm} / \mathrm{sec}$ paper speed. On each test trial, the interval immediately preceding stimulus onset was taken as the prestimulus baseline. On each test trial, the IIR response was measurcd as the largest bradycardiac response of the three consecutive intervals after prestimulus baseline. The HR responses were measured on the last trial of habituation, on the two test trials during training, and on the test trial delivered $1 \mathrm{hr}$ after training.

Repeated-measures factorial ANOVAs were conducted on the test stimulus parameters and HR responses. For all ANOVAs, significant interactions between factors were subjected to follow-up ANOVAs and post hoc Newman-Keuls analyses. Dependent and independent $t$ tests were used for single-factor comparisons. An $\alpha$-level of 0.05 was required for significant ANOVAs and $t$ tests (two-tailed).

\section{RESULTS}

These experiments included $105 \mathrm{mMG}$ single units recorded from 43 animals that received one session of classical or pseudoconditioning. The animals that received classical conditioning exhibited significant conditioned HR responses compared with the animals that received pseudoconditioning (see Training-related changes in test stimulus-evoked unit latency). In 14 of the classically conditioned animals, $19 \mathrm{mMG}$ cells were evoked reliably $(>70 \%$ timelocked unit discharges) by BIC stimulation at a latency of $<4.5$ $\mathrm{msec}$, and 16 cells were evoked reliably by SC stimulation at a latency of $<4.0 \mathrm{msec}$. To determine whether classical conditioning produced changes of synaptic efficacy on the auditory BIC inputs to $\mathrm{mMG}$ cells and not general changes of cellular excitability, analyses of synaptic efficacy were performed on only the mMG units that could be evoked by both BIC and SC stimulation. These analyses were also restricted to the $\mathrm{mMG}$ units that were evoked reliably and at latencies consistent with a monosynaptic projection. Thus, analyses of synaptic efficacy attributable to classical conditioning were performed on 9 cells (from 7 animals) that could be evoked reliably and at short latencies $(<3.5 \mathrm{msec}$ at 1.4-2.0 times threshold) from both BIC and SC. To determine whether changes of synaptic efficacy were attributable to associative learning, analyses were also performed on cells recorded from animals that received pseudoconditioning. In 11 pseudoconditioned animals, 10 cells were evoked reliably by BIC stimulation at a short latency, and 8 cells were evoked reliably by SC stimulation at a short latency. The priority in this study was to examine the mMG unit responses evoked by both BIC and SC test stimuli in animals that received classical conditioning; therefore, the animals that exhibited both BIC- and SC-evoked unit activity were administered classical conditioning rather than pseudoconditioning. Because of this priority, none of the cells from the pseudoconditioned animals was activated from both sites.

\section{Group comparisons for test stimulus-evoked unit activity}

To measure changes of synaptic efficacy, the latency, reliability, and spike trequency of test stimulus-evoked unit responding were analyzed for the pretraining, post-training, and $1 \mathrm{hr}$ post-training phases of stimulation at two threshold intensities. Unit responses could be grouped into only two of the three intensities $(0.8-1.4$ and 1.4-2.0 times threshold) administered during training because of the heterogeneity of unit response profiles encountered on a single stereotrode during the recording session. Table 1 shows the mean measures of the test stimulus-evoked mMG unit responses for each of the four groups analyzed in this study: unit responses from the neurons evoked reliably by both BIC (BICconditioning group; 9 cells) and SC (SC-conditioning group; 9 cells) test stimulation in classically conditioned animals; unit responses evoked reliably by BIC test stimulation in pseudoconditioned animals (BIC-pseudoconditioning group; 10 cells); and unit responses evoked reliably by $\mathrm{SC}$ test stimulation in pseudoconditioned animals (SC-pseudoconditioning group; 8 cells). Table 1 shows that the unit responses of each of the groups were evoked reliably and at a short latency $(<3.0 \mathrm{msec}$ at $1.4-2.0$ times threshold in the pretraining phase), consistent with monosynaptic projections.

Analyses compared the groups in Table 1 for each of the unit response measures: test stimulus-evoked unit response latency, reliability, and spike frequency. In these analyses the BICconditioning group was compared with the SC-conditioning group to determine the input-specific changes of synaptic efficacy related to conditioning. The BIC-conditioning group was compared with the BIC-pseudoconditioning group, and the SC-conditioning group was compared with the SC-pseudoconditioning group to determine whether changes of synaptic efficacy were attributable to associative processes. An initial set of repeated-measures ANOVAs was performed on the measures of test stimulus-evoked unit responding using a two-group $\times$ two-intensity $\times$ three-phase (pretraining, post-training, $1 \mathrm{hr}$ post-training) design. These analyses revealed no significant differences between the groups of unit response measures in the pretraining phase of test stimulation. Therefore, the test stimulus-evoked unit response measures were converted to change scores for purposes of clarity and easier interpretation of the changes of synaptic efficacy that resulted from training. Change scores were computed by subtracting each measure of each intensity calculated in the pretraining phase of stimulation from the corresponding measure calculated in the post-training and $1 \mathrm{hr}$ post-training phases of stimulation. The initial set of ANOVAs also revealed no significant main effects or interactions of intensity; therefore, $t$ test analyses were used for the group comparisons by collapsing across both intensities. A dependent $t$ test was also used for each individual group to determine whether the change in unit responding was significant from pretraining to post-training and from pretraining to $1 \mathrm{hr}$ post-training.

\section{Training-related changes in test stimulus-evoked unit latency}

Changes of synaptic efficacy were first measured in mMG by analyzing the training-induced change in test stimulus-evoked unit response latency. Figure $2 A$ shows the change in test stimulusevoked unit response latency immediately after training for each of the four groups of unit responses. Immediately after training, the BIC-conditioning group exhibited a significant decrease in the latency of test stimulus-evoked unit responding: $t_{(17)}=3.36, p=$ 0.004. The SC-conditioning group showed an increase in the latency of test stimulus-evoked unit responding after training that approached significance: $t_{(17)}=-1.99, p=0.062$. On the other hand, the BIC-pseudoconditioning and SC-pseudoconditioning groups showed no change or showed a small increase in the latency of test stimulus-cvoked unit responding after training. Analyses revealed that the change in test stimulus-evoked unit latency for the BIC-conditioning group was significantly different from that of the SC-conditioning group and the BICpseudoconditioning group: $t_{(17)}=-3.48, p=0.003$ and $t_{(36)}=$ 
Table 1. Mean measures of test stimulus-evoked mMG unit responses

\begin{tabular}{|c|c|c|c|c|c|c|}
\hline \multirow[b]{3}{*}{ Group } & \multicolumn{6}{|c|}{ Mean measures of evoked unit responding (SE) } \\
\hline & \multicolumn{2}{|c|}{$\begin{array}{l}\text { Unit response latency in } \\
\text { milliseconds }\end{array}$} & \multicolumn{2}{|c|}{$\begin{array}{l}\% \text { of time-locked unit } \\
\text { responses (reliability) }\end{array}$} & \multicolumn{2}{|c|}{$\begin{array}{l}\text { Evoked spike frequency in } \\
\text { standard units }\end{array}$} \\
\hline & $\begin{array}{l}0.8-1.4 \times \\
\text { threshold }\end{array}$ & $\begin{array}{l}1.4-2.0 \times \\
\text { threshold }\end{array}$ & $\begin{array}{l}0.8-1.4 \times \\
\text { threshold }\end{array}$ & $\begin{array}{l}1.4-2.0 \times \\
\text { threshold }\end{array}$ & $\begin{array}{l}0.8-1.4 \times \\
\text { threshold }\end{array}$ & $\begin{array}{l}1.4-2.0 \times \\
\text { threshold }\end{array}$ \\
\hline \multicolumn{7}{|l|}{ BIC test stimulus } \\
\hline \multicolumn{7}{|c|}{$\begin{array}{l}\text { Classical conditioning } \\
\quad(9 \text { cells })\end{array}$} \\
\hline Pretraining & $\begin{array}{l}2.73 \\
( \pm 0.3)\end{array}$ & $\begin{array}{l}2.34 \\
( \pm 0.2)\end{array}$ & $\begin{array}{l}67.8 \\
( \pm 8.6)\end{array}$ & $\begin{array}{l}77.2 \\
( \pm 7.6)\end{array}$ & $\begin{array}{l}9.0 \\
( \pm 3.0)\end{array}$ & $\begin{array}{l}11.6 \\
( \pm 3.8)\end{array}$ \\
\hline Post-training & $\begin{array}{l}2.21 \\
( \pm 0.2)\end{array}$ & $\begin{array}{l}1.93 \\
( \pm 0.2)\end{array}$ & $\begin{array}{l}77.3 \\
( \pm 6.5)\end{array}$ & $\begin{array}{l}89.5 \\
( \pm 4.1)\end{array}$ & $\begin{array}{l}11.5 \\
( \pm 3.7)\end{array}$ & $\begin{array}{l}12.3 \\
( \pm 3.5)\end{array}$ \\
\hline \multicolumn{7}{|c|}{$\begin{array}{l}\text { Pseudoconditioning } \\
10 \text { cells }\end{array}$} \\
\hline Pretraining & $\begin{array}{l}2.88 \\
( \pm 0.1)\end{array}$ & $\begin{array}{l}2.67 \\
( \pm 0.2)\end{array}$ & $\begin{array}{l}67.2 \\
( \pm 7.2)\end{array}$ & $\begin{array}{l}79.8 \\
( \pm 5.9)\end{array}$ & $\begin{array}{l}5.9 \\
( \pm 2.0)\end{array}$ & $\begin{array}{l}6.8 \\
( \pm 2.1)\end{array}$ \\
\hline Post-training & $\begin{array}{l}2.90 \\
( \pm 0.1)\end{array}$ & $\begin{array}{l}2.98 \\
( \pm 0.2)\end{array}$ & $\begin{array}{l}65.0 \\
( \pm 7.5)\end{array}$ & $\begin{array}{l}70.8 \\
( \pm 9.1)\end{array}$ & $\begin{array}{l}4.1 \\
( \pm 2.2)\end{array}$ & $\begin{array}{l}6.4 \\
( \pm 2.1)\end{array}$ \\
\hline \multirow{2}{*}{\multicolumn{7}{|c|}{$\begin{array}{l}\text { SC test stimulus } \\
\text { Classical conditioning } \\
\quad(9 \text { cells })\end{array}$}} \\
\hline & & & & & & \\
\hline & $\begin{array}{l}2.97 \\
( \pm 0.4)\end{array}$ & $\begin{array}{l}2.10 \\
( \pm 0.3)\end{array}$ & $\begin{array}{l}62.4 \\
( \pm 10.2)\end{array}$ & $\begin{array}{l}85.3 \\
( \pm 6.8)\end{array}$ & $\begin{array}{l}8.9 \\
( \pm 3.0)\end{array}$ & $\begin{array}{l}12.4 \\
( \pm 2.3)\end{array}$ \\
\hline Post-training & $\begin{array}{l}3.16 \\
( \pm 0.5)\end{array}$ & $\begin{array}{l}2.73 \\
( \pm 0.3)\end{array}$ & $\begin{array}{l}57.3 \\
( \pm 8.9)\end{array}$ & $\begin{array}{l}66.4 \\
( \pm 8.0)\end{array}$ & $\begin{array}{l}7.1 \\
( \pm 2.5)\end{array}$ & $\begin{array}{l}8.4 \\
( \pm 2.6)\end{array}$ \\
\hline \multicolumn{7}{|c|}{ Pseudoconditioning 8 cells } \\
\hline Pretraining & $\begin{array}{l}2.80 \\
( \pm 0.3)\end{array}$ & $\begin{array}{l}2.90 \\
( \pm 0.4)\end{array}$ & $\begin{array}{l}70.9 \\
( \pm 7.2)\end{array}$ & $\begin{array}{l}74.6 \\
( \pm 7.0)\end{array}$ & $\begin{array}{l}8.4 \\
( \pm 2.6)\end{array}$ & $\begin{array}{l}7.1 \\
( \pm 2.4)\end{array}$ \\
\hline Post-training & $\begin{array}{l}3.20 \\
( \pm 0.4)\end{array}$ & $\begin{array}{l}3.00 \\
( \pm 0.4)\end{array}$ & $\begin{array}{l}55.4 \\
( \pm 9.9)\end{array}$ & $\begin{array}{l}67.1 \\
( \pm 10.6)\end{array}$ & $\begin{array}{l}4.0 \\
( \pm 2.6)\end{array}$ & $\begin{array}{l}6.4 \\
( \pm 2.4)\end{array}$ \\
\hline
\end{tabular}

$-4.57, p=0.0001$, respectively. These analyses of test stimulusevoked unit response latency suggest that classical conditioning increases the efficacy of the BIC synapses carrying auditory CS information to $\mathrm{mMG}$ cells compared with control synapses. Examination of the test stimulus-evoked unit response latency of the 9 individual neurons evoked from both sites in animals that received classical conditioning revealed that 7 of 9 neurons showed decreases in BIC-evoked unit latency, and 6 of 9 neurons showed increases in SC-evoked unit latency immediately after conditioning.

\section{Training-related changes in reliability of test stimulus- evoked unit responses}

Changes of synaptic efficacy were also measured in $\mathrm{mMG}$ by analyzing the training-induced change in the reliability of test stimulus-evoked unit responses. The reliability of evoked unit responses was measured as the percentage of time-locked stimulus-evoked unit responses. Figure $2 B$ shows the change in the reliability of test stimulus-evoked unit responses immediately after training for each of the four groups of unit responses. Immediately after training, the BIC-conditioning group exhibited an increase in the reliability of test stimulus-evoked unit responding: $t_{(17)}=-2.47, p=0.025$. On the other hand, the SCconditioning and SC-pseudoconditioning groups showed a decrease in the reliability of test stimulus-evoked unit responding: $t_{(17)}=2.26, p=0.037$ and $t_{(15)}=3.80, p=0.002$, respectively.
The BIC-pseudoconditioning group showed only a snill decrease in the reliability of evoked unit responding. Analyses revealed that the change in the reliability of test stimulus-evoked unit responding in the BIC-conditioning group was significantly different from that of the SC-conditioning group and the BIC-pseudoconditioning group: $t_{(17)}=2.89, p=0.010$ and $t_{(36)}=2.60, p=0.013$, respectively. These analyses of test stimulus-evoked unit reliability suggest that classical conditioning increases the efficacy of the BIC synapses carrying auditory CS information to $\mathrm{mMG}$ cells compared with control synapses. Examination of the test stimulus-evoked unit re sponse reliability of the 9 individual neurons evoked from both sites in animals that received classical conditioning revealed that 6 of 9 neurons showed increases in BrC-evoked unit reliability, and 6 of 9 neurons showed decreases in SC-evoked unit reliability immediately after conditioning.

\section{Training-related changes in test stimulus-evoked spike frequency}

Analyses of synaptic efficacy were also performed by measuring the training-induced change in test stimulus-evoked mMG spike frequency. Figure $2 C$ shows the change in test stimulus-evoked spike frequency in standard units immediately after training for each of the four groups of unit responses. Immediately after training, the BIC-conditioning group exhibited an increase in test stimulus-evoked spike frequency: $t_{(17)}=-2.43, p=0.026$. On the other hand, the SC-conditioning and SC-pseudoconditioning 


\section{IMMEDIATELY AFTER TRAINING}

A.

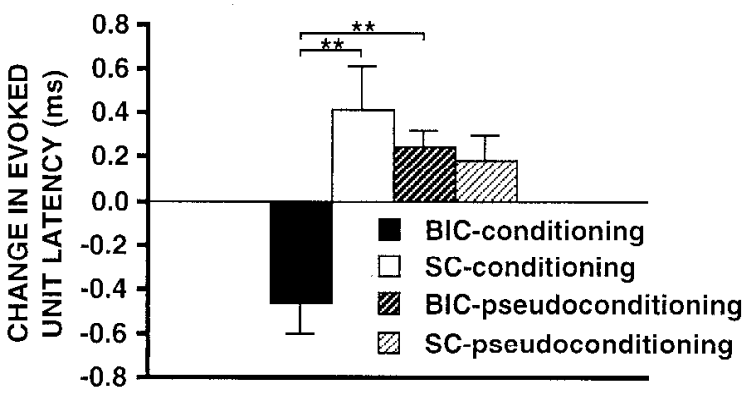

B.

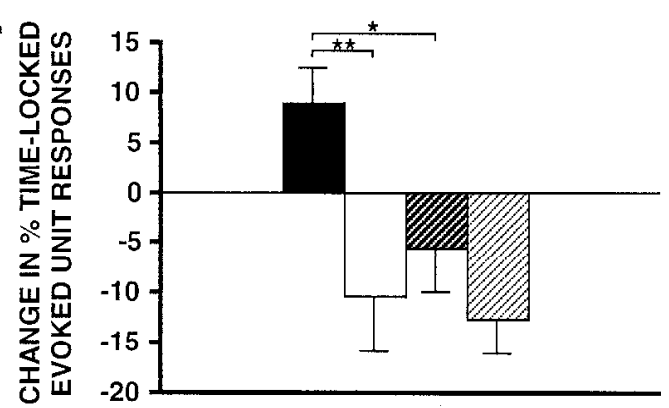

C.

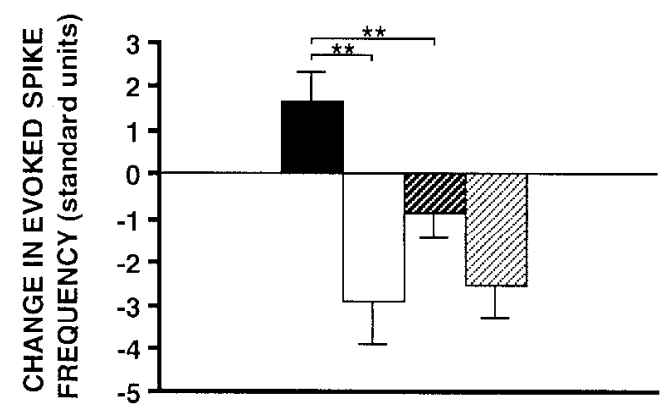

Figure 2. Mean change in test stimulus-evoked unit response latency $(A)$, reliability ( $B ; \%$ time-locked unit responses), and spike frequency $(C)$ immediately after training. Values obtained in the pretraining phase of stimulation were subtracted from values obtained in the post-training phase of stimulation. In animals that received IIR conditioning, neurons in the medial subnucleus of the mMG were activated by test stimuli delivered to both sites, the BIC (black bar, BIC-conditioning) and the SC (white bar, SC-conditioning). In animals that received HR pseudoconditioning, mMG neurons were activated by test stimuli delivered to BIC (bar with thick diagonal lines, BIC-pseudoconditioning) or SC (bar with thin diagonal lines, SC-pseudoconditioning). Asterisks indicate significant group comparisons $\left({ }^{*} p<0.05 ;{ }^{* *} p<0.01\right)$. Comparison of the BIC-conditioning group with control groups suggests that conditioning-related plasticity occurs at the synapses carrying auditory CS information. Bars indicate SE.

groups showed a decrease in test stimulus-evoked spike frequency: $t_{(17)}=2.94, p=0.009$ and $t_{(15)}=2.15, p=0.049$, respectively. The BIC-pseudoconditioning group showed only a small decrease in evoked spike frequency. Analyses revealed that the change in test stimulus-evoked spike frequency in the BICconditioning group was significantly different from the SCconditioning group and the BIC-pseudoconditioning group: $t_{(17)}$ $=3.71, p=0.002$ and $t_{(36)}=2.92, p=0.006$, respectively. Examination of the test stimulus-evoked spike frequency of the 9 individual neurons evoked from both sites in animals that received classical conditioning revealed that 7 of 9 neurons showed
Table 2. Baseline frequency of spontaneous unit discharge across training

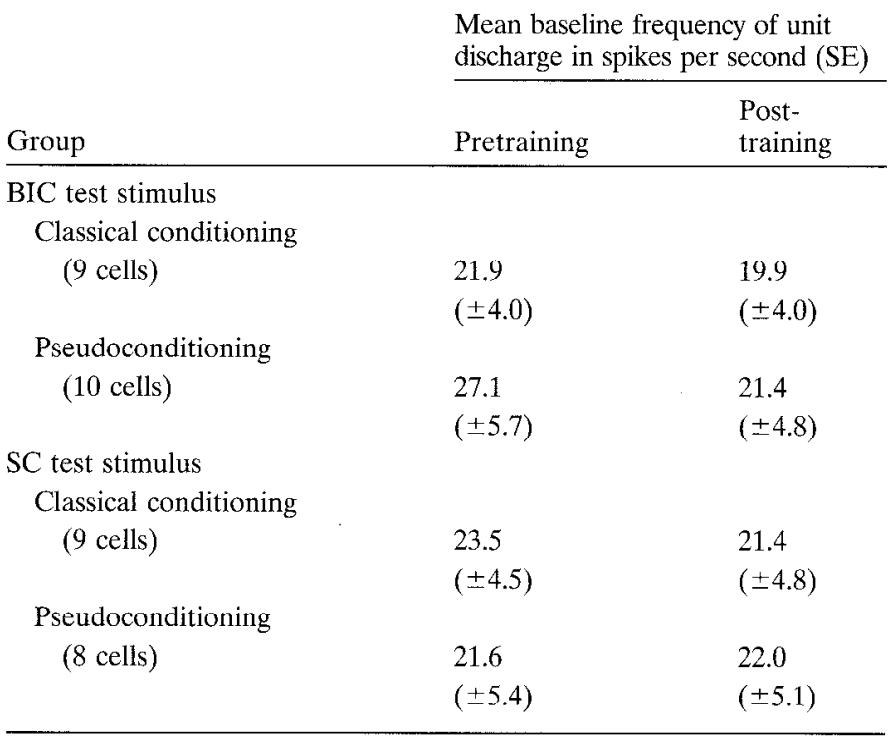

increases in BIC-evoked spike frequency, and 7 of 9 neurons showed decreases in SC-evoked spike frequency immediately after classical conditioning.

\section{Changes in spontaneous MMG unit activity}

The baseline frequency of spontaneous unit discharge before the delivery of test stimuli was analyzed to determine whether the learning-related changes in test stimulus-evoked unit responding were attributable to changes in baseline activity. Table 2 shows the mean baseline unit frequency in the pre- and post-training phase of stimulation for each of the four groups of unit responses. Individual dependent $t$ tests compared the baseline spontaneous unit frequency in the pre- and post-training phases of stimulation for each of the four groups. These tests revealed no significant effects, suggesting that the learning-related changes in test stimulus-evoked unit responding were not attributable to changes in baseline spontaneous unit frequency.

\section{Long-term training-related changes of synaptic efficacy}

Test stimulus-evoked unit activity was also measured $1 \mathrm{hr}$ posttraining and compared with the activity in the pretraining phase of stimulation to examine the long-term changes in synaptic efficacy. Figure 3 shows the training-induced changes in test stimulusevoked unit latency, reliability, and spike frequency for the four groups of unit responses $1 \mathrm{hr}$ post-training. This figure shows that $1 \mathrm{hr}$ after training the change in unit responding in the BICconditioning group has diminished; however, the relationship of the four groups of unit responses still persists. Specifically, the SC-conditioning group still exhibited a significant change in test stimulus-evoked unit response latency, reliability, and spike frequency $1 \mathrm{hr}$ after training: $t_{(17)}=-2.27, p=0.037 ; t_{(17)}=3.29$, $p=0.004$; and $t_{(17)}=2.11, p=0.05$, respectively. Analyses revealed that the change in test stimulus-evoked unit response rcliability and spike frcquency in the BIC-conditioning group was significantly different from the SC-conditioning group: $t_{(17)}=$ $2.38, p=0.029$ and $t_{(36)}=2.12, p=0.049$, respectively. The BIC-conditioning group, however, was significantly different from the BIC-pseudoconditioning group only on the measure of test 


\section{HOUR AFTER TRAINING}
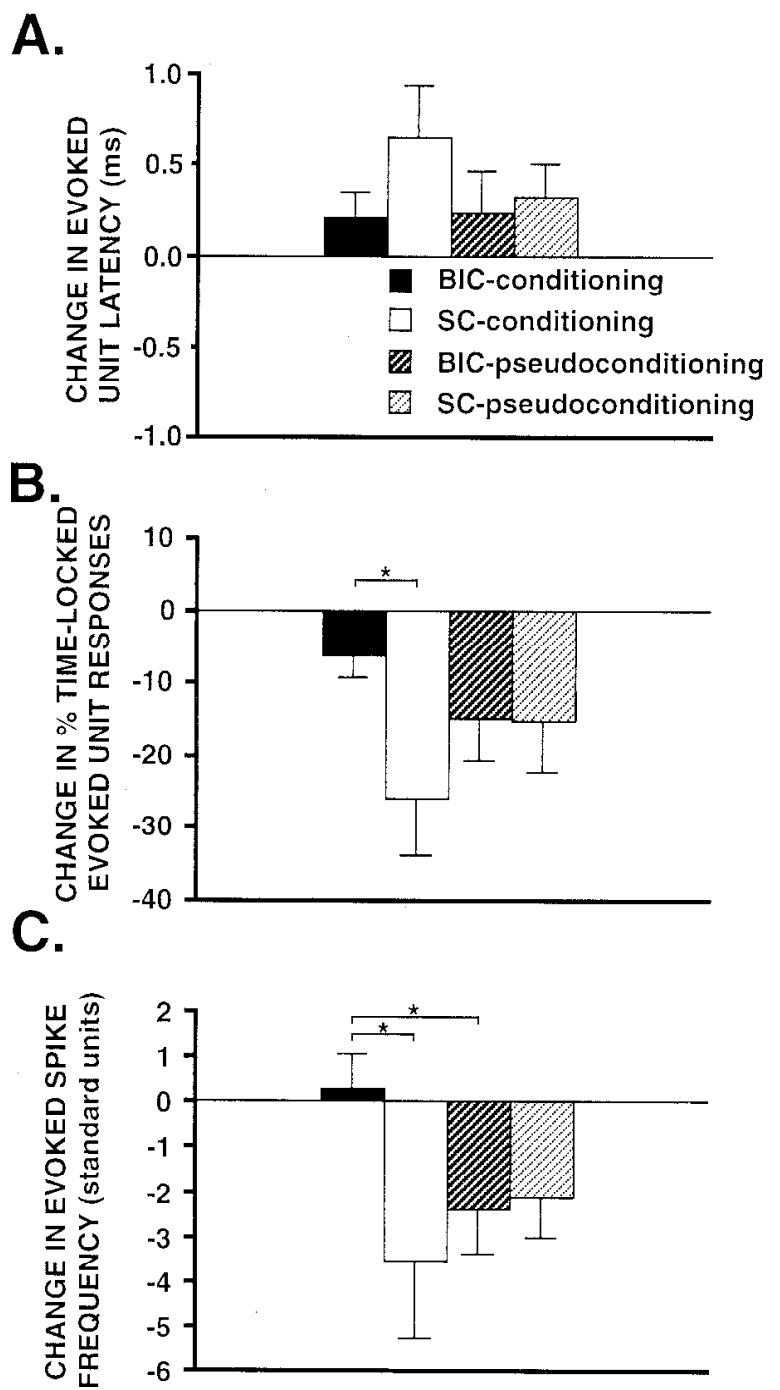

Figure 3. Mean change in test stimulus-evoked unit response latency $(A)$, reliability ( $B ; \%$ time-locked unit responses), and spike frequency $(C) 1 \mathrm{hr}$ after training. Values obtained in the pretraining phase of stimulation were subtracted from values obtained $1 \mathrm{hr}$ post-training. In animals that received HR conditioning, neurons in the medial nucleus of the $\mathrm{mMG}$ were activated by test stimuli delivered to both sites, the BIC (hlack har, BIC-conditioning) and the SC (white bar, SC-conditioning). In animals that received HR pseudoconditioning, $\mathrm{mMG}$ neurons were activated by test stimuli delivered to $\mathrm{BIC}$ (bar with thick diagonal lines, BIC pseudoconditioning) or $\mathrm{SC}$ (bar with thin diagonal lines, $S C$-pseudoconditioning). The relationship among the four groups of unit responses suggests that some learning-related synaptic changes may still be evident $1 \mathrm{hr}$ after conditioning. Asterisks indicate significant group comparisons $(p<0.05)$. Bars indicate SE.

stimulus-evoked spike frequency: $t_{(36)}=2.12, p=0.041$. These analyses suggest that some of the conditioning-induced changes of synaptic efficacy at the BIC inputs to mMG cells persist $1 \mathrm{hr}$ after training. However, this finding should be interpreted with caution, because the changes in unit responding in the BIC-conditioning group diminished greatly $1 \mathrm{hr}$ after conditioning.

Figure 4 shows example histograms of a neuron evoked by both $\mathrm{BIC}$ and SC test stimuli before, immediately after, and $1 \mathrm{hr}$ after classical HR conditioning. The histograms show an increased number of BIC-evoked unit responses at shorter latencies (2-3 msec after test stimulus onset) immediately after conditioning.

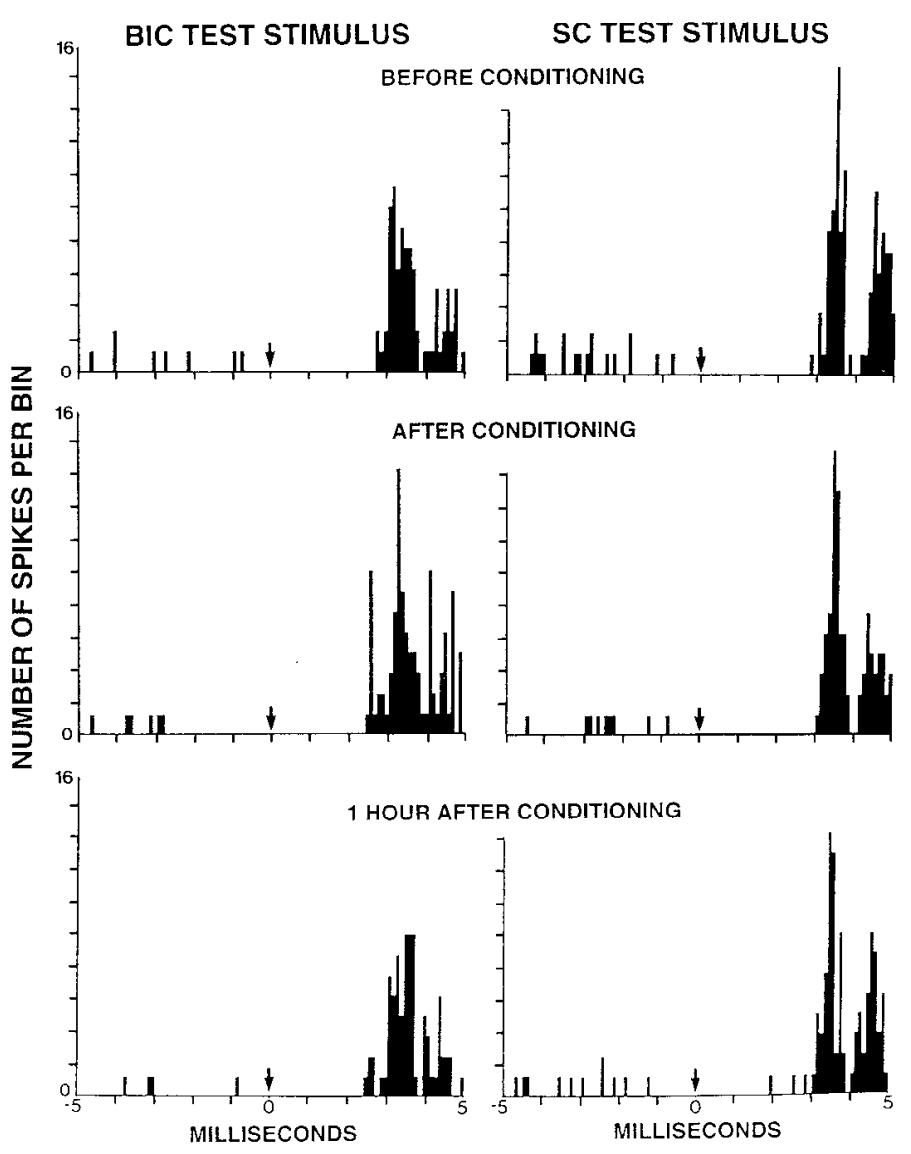

Figure 4. Histograms of a single mMG neuron activated by both $B I C$ test (left) and $S C$ test (right) stimuli before (top), immediately after (middle), aud $1 \mathrm{hr}$ after (bottom) one session of classical HR conditioning. For each histogram, spikes were grouped in $0.1 \mathrm{msec}$ bins and summed across 50 presentations of a test stimulus. The $y$-axes indicate number of spikes per bin, and the $x$-axes indicate $5 \mathrm{msec}$ before and $5 \mathrm{msec}$ after test stimulus onset (arrow). After conditioning, BIC test stimulus-evoked activity exhibited an increase in the number of short-latency evoked unit responses. The $\mathrm{SC}$ test stimulus-evoked activity was unaffected by conditioning.

The SC-evoked unit activity was relatively unchanged by conditioning.

\section{Latency measures of antidromically activated BIC and SC units}

The latency of the monosynaptic projections from both sites to $\mathrm{mMG}$ was examined by measuring the latency of BIC and SC unit responses activated antidromically from $\mathrm{mMG}$. These antidromic measures were used as a reference to determine whether the latencies of the four groups of orthodromic unit responses recorded during training were consistent with monosynaptic latencies. Tests were performed using 10 animals, which yiclded 44 BIC and $27 \mathrm{SC}$ units that were activated antidromically. The average latency of these antidromically activated units in BIC and SC was $1.52 \mathrm{msec}$ (range $0.5-2.5 \mathrm{msec}$ ) and $1.32 \mathrm{msec}$ (range 0.5-2.5 $\mathrm{msec}$ ), respectively. Collision tests were performed successfully on 20 of the $\mathrm{BIC}$ and 10 of the SC units, providing additional evidence that these units were activated antidromically. The latency of this subset of antidromically activated BIC and SC units was $1.54 \mathrm{msec}$ (range $0.8-2.3 \mathrm{msec}$ ) and $1.41 \mathrm{msec}$ (range 0.5-2.5 msec), respectively. Figure 5 shows examples of successful collision tests performed on antidromically activated BIC and SC units. Drifting of the electrode and other technical limitations 
A. STIMULATION: mMG

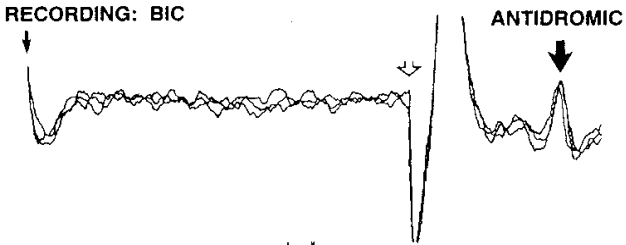

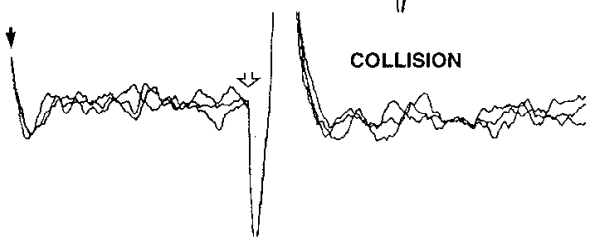

B. STIMULATION: MMG

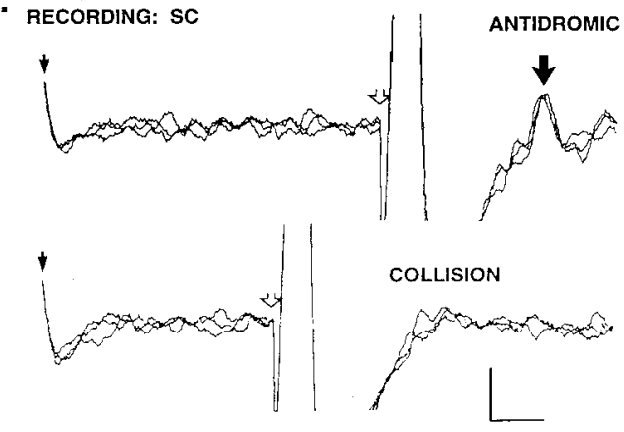

Figure 5. Antidromically activated units and subsequent collision with spontaneous spike. $A$, An electrical stimulus (open arrow) in the $m M G$ produced an antidromic unit (large black arrow in top three traces) recorded in the $B I C$ at a latency of $1.7 \mathrm{msec}$ when the interval between the spontaneous spike (small black arrow) and the stimulus was greater than the critical delay. Collision (bottom three traces) occurred when the interval between the spontaneous spike and the stimulus was less than the critical delay. $B$, An electrical stimulus in $m M G$ produced an antidromic unit (top three traces) recorded in the $S C$ with a latency of $1.8 \mathrm{msec}$ when the interval between the spontaneous spike and the stimulus was greater than the critical delay. Collision (bottom three traces) occurred when the interval between the spontaneous spike and the stimulus was less than the critical delay. Note that a small portion of the sweeps in $B$ has been cut off by the stimulus artifact. The latency of these antidromic units suggests that the latency of the BIC- and SC-evoked units recorded during training were consistent with monosynaptic latencies. Negative voltage is upward. Calibration: $100 \mu \mathrm{V}, 1 \mathrm{msec}$.

often prevented successful collision tests on the remaining antidromic units. This set of tests suggests that the latencies of the orthodromic units generated from BIC (mean $2.51 \mathrm{msec}$ ) and SC (mean $2.48 \mathrm{msec}$ ) in the four groups of unit responses recorded during training (at 1.4-2.0 times threshold in the pretraining phase of stimulation) were consistent with a monosynaptic projection that included a short synaptic delay.

\section{Histological location of stimulating and recording electrodes}

The locations of the stimulating and recording electrodes implanted in the four groups of animals analyzed in this study are shown on coronal sections in Figure 6. The tips of the recording electrodes were verified histologically and found to be located within mMG. It is important to note that several of the recording electrodes were implanted near the dorsal border of mMG. Most of the tips of the SC-stimulating electrodes were found to be located in the deep ventral layers of this structure at the rostralcaudal level of the oculomotor nucleus. Most of the BIC-

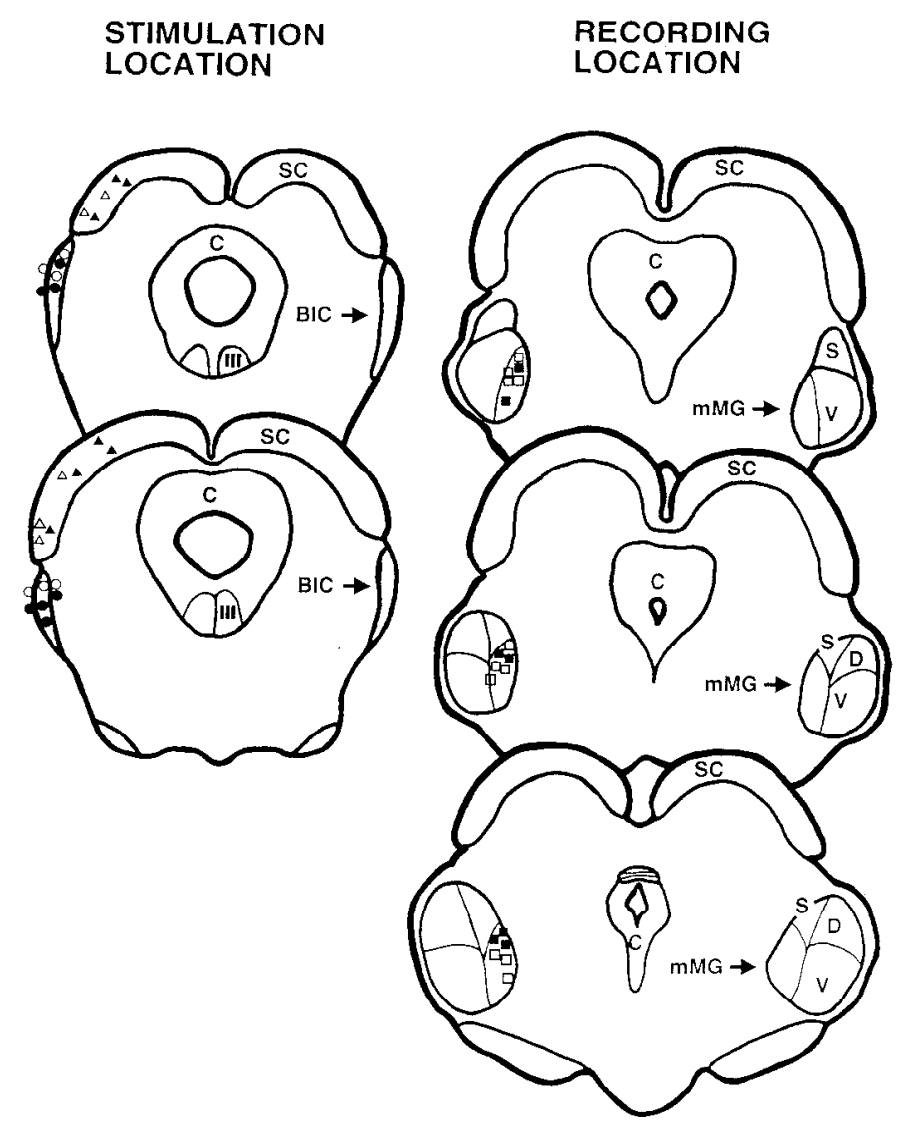

Figure 6. Ilistological location of the stimulating clcctrodes in the $B I C$ (circles) and SC (triangles), and recording electrodes in the medial subnucleus of the $m M G$ (squares) for the conditioned (closed symbols) and pseudoconditioned (open symbols) groups analyzed in this study. $C$, Central gray; $D$, dorsal nucleus of the mMG; $S$, suprageniculate; $V$, ventral nucleus of the mMG; III, oculomotor nucleus.

stimulating electrodes were also found to be located at the rostral-caudal level of the oculomotor nucleus.

\section{Training-related changes of $\mathrm{HR}$ responses}

Figure 7 shows the mean HR responses to the CS across training for the conditioned $(n=7)$ and pseudoconditioned $(n=11)$ animals from which the four groups of neurons were recorded. The animals that received classical conditioning exhibited larger bradycardiac responses to the CS during and $1 \mathrm{hr}$ after training compared with the pseudoconditioned animals. An initial $t$ test analysis compared HR responses of the conditioned and pseudoconditioned animals before training and revealed no significant difference: $t_{(16)}=-0.72, p=0.5$. The HR changes from baseline on CS test trials were then subjected to a repeated measures ANOVA that included a training groups factor (conditioned and pseudoconditioned animals) and a test trials factor (last test trial of habituation, 2 test trials during training, 1 test trial $1 \mathrm{hr}$ after training). The analysis revealed a significant effect of training groups and test trials: $F_{(1,16)}=12.22, p=0.003$ and $F_{(3,48)}=8.54, p=0.0001$, respectively. Post hoc tests conducted on the test trials effect (mean square within $=58.62$ ) revealed that the HR responding $1 \mathrm{hr}$ after training was greater than on previous test trials. These analyses show that the animals that received classical conditioning exhibited associative responses to the auditory $\mathrm{CS}$ as the result of classical HR conditioning. In these 


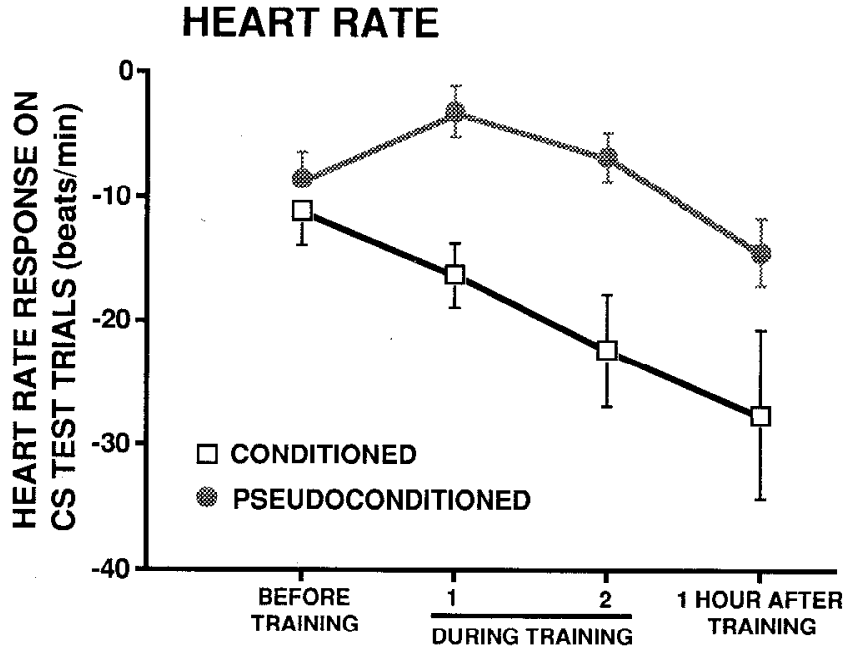

Figure 7. Mean HR responses to the CS across training for the conditioned (open squares; $n=7$ ) and pseudoconditioned (shaded circles; $n=$ 11) animals from which the four groups of neurons were recorded. The HR responses before, during, and $\mathbf{1}$ hr after training were computed on CS test trials as the largest bradycardiac response from baseline (beats/min). Bars indicate SE.

animals, auditory inputs to $\mathrm{mMG}$ cells increased in synaptic efficacy.

\section{DISCUSSION}

The results of the present study demonstrate that auditory synaptic inputs to $\mathrm{mMG}$ ncurons increase in strength as a result of classical conditioning with an acoustic CS. Specifically, BIC test stimulus-evoked unit activity exhibited the following changes immediately after conditioning: decreases in unit response latency, increases in unit response reliability, and increases in spike frequency. Conversely, SC-evoked unit responses from the same neurons showed opposite changes in test stimulus-evoked unit responding immediately after conditioning. Some of these synaptic changes may have persisted for $1 \mathrm{hr}$ after conditioning. Furthermore, BIC and SC inputs showed no changes or decreases in synaptic efficacy after pseudoconditioning.

\section{Measurement of learning-related synaptic efficacy in $\mathbf{m M G}$}

To provide evidence that the training-induced changes in unit responding were attributable to changes in the efficacy of auditory $\mathrm{BIC}$ inputs and not to general changes of cellular excitability, analyses of synaptic efficacy were performed using only the $\mathrm{mMG}$ units that could be evoked by both BIC and SC stimulation. Because of the technical demands of this type of design, only 9 cells met this criterion; however, the BIC-evoked unit responses exhibited robust learning-related synaptic changes compared with those of the SC control-evoked responses. This is consistent with the notion that the learning-related changes in unit responding were attributable to the strengthening of BIC inputs and not to general cellular changes that would influence both BIC- and $\mathrm{SC}$-evoked responses. Despite these within-cell control procedures, we cannot rule out the possibility that the conditioningrelated alterations in evoked unit responding were caused by threshold changes in BIC axons rather than synaptic strengthening at BIC synapses. For example, tonic depolarization of BIC cells could have lowered the stimulation threshold for these axons, causing a larger afferent fiber volley. Tonic depolarization large enough to produce threshold changes, however, would also likely produce increases in spontaneous activity along those fibers as well as a corresponding increase in $\mathrm{mMG}$ spontaneous activity. Increases in $\mathrm{mMG}$ spontaneous activity were not observed; therefore, the most likely interpretation is that strengthening occurred at $\mathrm{BIC}$ synapses.

Only the BIC and SC sites that evoked unit responses consistent with a monosynaptic projection were used in the analyses of synaptic efficacy. This criterion was used to provide evidence that changes of synaptic efficacy occurred at the synaptic inputs to neurons in $\mathrm{mMG}$ and not in another structure outside of $\mathrm{mMG}$ via a polysynaptic connection. Previous anatomical evidence has shown that $\mathrm{IC}$ and $\mathrm{SC}$ send monosynaptic projections to $\mathrm{mMG}$ neurons. In the present study, antidromic latencies recorded in $\mathrm{BIC}$ and SC suggest that the unit responses evoked during training were consistent with latencies of monosynaptic projections. Similar antidromic latencies $(1.0-2.0 \mathrm{msec})$ have been recorded in SC during thalamic stimulation (Chevalier and Deniau, 1984). Furthermorc, cxpcriments cxamining auditory cvoked unit activity suggest that the latency delay from BIC to $\mathrm{mMG}$ is $\sim 2.5 \mathrm{msec}$ (Ades and Brookhart, 1950). Together, these studies provide evidence that the latencies of the $\mathrm{mMG}$ unit responses evoked in this study (3.0 msec at 1.4-2.0 times threshold, pretraining) were consistent with the latency of monosynaptic projections. The antidromic latency controls, however, do not rule out the possibility that some unit responses recorded during training may have been mediated by a short latency interneuron. Nevertheless, the evoked unit response latencies do suggest that any conditioningrelated synaptic changes that may have included an interneuron most likely occurred within the structure of $\mathrm{mMG}$.

To provide evidence that the conditioning-related increases of synaptic efficacy were attributable to associative learning, test stimulus-evoked unit response measures were also obtained from animals that received pseudoconditioning. The priority in this study, however, was to examine mMG unit responses cvoked by both BIC and SC test stimuli in animals that received classical conditioning; therefore, animals that exhibited both BIC- and SC-evoked unit activity were administered classical conditioning rather than pseudoconditioning. Because of this priority, none of the cells from the pseudoconditioned animals were activated from both sites. Clearly, stronger conclusions could be reached if BIC and SC inputs to the same cells were tested during pseudoconditioning. For instance, we cannot rule out the possibility that a different $\mathrm{mMG}$ cell population was sampled during pseudoconditioning. Nevertheless, the test stimulus-evoked unit response measures obtained from separate pseudoconditioned animals suggests that neither BIC nor SC synapses increase in efficacy as a result of pseudoconditioning. This provides evidence that the increases of synaptic efficacy at the BIC inputs were specific to conditioning. It is also important to note that the same procedures were used for the placement of all electrodes, and histological examination revealed no differences in electrode placement between the groups. In addition, a few of the pseudoconditioned cells could be evoked from both sites, but technical failures, such as excessive artifact, precluded obtaining data from one of the sites.

\section{Short- versus long-term changes of synaptic efficacy}

In this study, most of the conditioning-related changes of synaptic efficacy at the BIC inputs diminished $1 \mathrm{hr}$ after training. The relationship among data from the four groups, however, suggests that some learning-related synaptic changes may still be evident 1 hr after conditioning. These long-term BIC synaptic changes 
should be interpreted with caution because the test stimulusevoked unit response measures for the BIC-conditioning group diminished greatly, whereas the SC-conditioning group still exhib ited a large decrease in test stimulus-evoked unit responding $1 \mathrm{hr}$ after conditioning. This large decrease in test stimulus-evoked unit responding in the $\mathrm{SC}$-conditioning group could reflect longterm synaptic depression of the SC-control synapses, independent of the efficacy of the BIC synapses on the same mMG cells. On the other hand, the large decreases in test stimulus-evoked unit reliability and spike frequency in the SC-conditioning and BICpseudoconditioning groups $1 \mathrm{hr}$ after training could be attributable to state changes in the animals caused by the extended training period.

The short-term synaptic changes found in $\mathrm{mMG}$ are consistent with a model of learning proposed by Weinberger et al. (1990), which suggests that neuronal plasticity that develops in $\mathrm{mMG}$ could serve to influence other structures in the conditioning circuitry, such as the amygdala and the auditory cortex. Thus, it is possible that short-term learning related plasticity in $\mathrm{mMG}$ serves to influence other structures in which more long-term changes occur. Learning-related changes in $\mathrm{mMG}$ neuronal activity, however, have been shown to persist beyond $1 \mathrm{hr}$ (Edeline and Weinberger, 1992). This suggests that the synaptic changes in $\mathrm{mMG}$ observed in the present study may contribute to long-term neuronal changes in this structure or that the long-term changes in mMG neuronal activity reported in other studies reflect plasticity occurring elsewhere in the conditioning circuitry.

This study demonstrated that changes in mMG occur quickly during autonomic conditioning (i.e., $<20$ trials). Studies examining neural changes during somatomotor eyeblink conditioning, however, have found that changes in the cerebellum develop more slowly across training (McCormick and Thompson, 1984). These differences in time course support the notion that these are different classes of conditioned responses that may require distinct neural processes (Lenartz and Weinberger, 1992). Behavioral evidence also suggests that these paradigms use distinct neural circuits, because lesions of $\mathrm{mMG}$ have been shown to disrupt the conditioning of HR responses but not the conditioning of motoric eye responses (Jarrell et al., 1986).

\section{Anatomical considerations}

This study provides evidence that learning-related synaptic changes can occur in sensory structures such as mMG. Most of the cells examined for changes of synaptic efficacy were situated in the dorsal portion of $\mathrm{mMG}$; however, the ventral portion of $\mathrm{mMG}$ and the adjacent posterior intralaminar nucleus are also possible sites of plasticity (LeDoux et al., 1990; Cruikshank et al., 1992; Edeline and Weinberger, 1992; McEchron et al., 1995). Neurons were most likely recorded in this dorsal portion of $\mathrm{mMG}$ because this seems to be the area receiving overlapping projections from BIC and SC (Holstege and Collewijn, 1982). Thus, synaptic efficacy was not examined for the more ventral mMG cells because these cells could not be evoked from SC. Nevertheless, BIC inputs to the cells in the ventral $\mathrm{mMG}$ and the posterior intralaminar nucleus probably also exhibit plasticity. Furthermore, evidence suggests that other areas of the HR-conditioning circuit, such as the auditory cortex and amygdala, may also show learning-related changes of synaptic efficacy (Weinberger et al., 1995).

\section{Possible mechanism for synaptic changes in $\mathrm{mMG}$}

The synaptic changes obtained in this study are consistent with a Hebbian mechanism of plasticity (Hebb, 1949) using CS and US synaptic convergence on $\mathrm{mMG}$ cells. Specifically, US inputs activated shortly after CS-synaptic transmission may provide the increased activity necessary for the strengthening of CS inputs. This mechanism could explain why BIC inputs that are active during CS-US presentations increase in strength and why SC inputs that are not active during CS-US presentations do not increase in strength and may even decrease in strength. This weakening of SC inputs may involve mechanisms similar to synaptic depression or depotentiation (Fujii et al., 1991; Mulkey and Malenka, 1992).

\section{REFERENCES}

Ades HW, Brookhart JM (1950) The central auditory pathway. J Neurophysiol 13:189-206.

Aitkin LM (1973) Medial geniculate body of the cat responses to tonal stimuli of neurons in the medial division. J Neurophysiol 36:275-283.

Altnan J, Carpenter MB (1961) Fiber projections of the superior colliculus in the cat. J Comp Neurol 116:157-177.

Andersen P, Sundberg SH, Sveen O, Swann JW, Wigstrom H (1980) Possible mechanisms for long-lasting potentiation of synaptic transmission in hippocampal slices from guinea-pigs. J Physiol (Lond) 302:463-482.

Bliss TVP, Lomo T (1973) Long-lasting potentiation of synaptic transmission in the dentate area of the anaesthetized rabbit following stimulation of the perforant path. I Physiol (I ond) 232:331-356.

Calford MB, Aitkin LM (1983) Ascending projections to the medial geniculate body of the cat: evidence for multiple parallel auditory pathways through thalamus. J Neurosci 3:2365 2380.

Chevalier G, Deniau JM (1984) Spatio-temporal organization of a branched tecto-spinal/tecto-diencephalic neuronal system. Neuroscience 12:427-439.

Cruikshank SD, Edeline J-M, Weinberger NM (1992) Stimulation at a site of auditory-somatosensory convergence in the medial geniculate nucleus is an effective unconditioned stimulus for fear conditioning. Behav Neurosci 106:471-483.

Edeline J-M, Weinberger NM (1992) Associative retuning in the thalamic source of input to the amygdala and auditory cortex: receptive field plasticity in the medial division of the medial geniculate body. Behav Neurosci 106:81-105.

Erzurumlu RS, Killackey HP (1980) Diencephalic projections of the subnucleus interpolaris of the brainstem trigeminal complex in the rat. Neuroscience 5:1891-1901.

Fujii S, Saito K, Miyakawa H, Ito K, Kato H (1991) Reversal of longterm potentiation (depotentiation) induced by tetanic stimulation of the input to CA1 neurons of guinea pig hippocampal slices. Brain Res 555:112-122.

Gabriel M, Saltwick SE, Miller JD (1975) Conditioning and reversal of short-latency multiple unit responses in the rabbit medial geniculate nucleus. Science 189:1108-1109.

Gerren R, Weinberger NM (1983) Long term potentiation in the magnocellular medial geniculate nucleus of the anesthetized cat. Brain Res 265:138-142.

Graham J (1977) An autoradiographic study of the efferent connections of the superior colliculus in the cat. J Comp Neurol 173:629-654.

Hebb DO (1949) Organization of behavior. New York: Wiley.

Holstege G, Collewijn H (1982) The effcrent connections of the nuclcus of the optic tract and the superior colliculus in the rabbit. J Comp Neurol 209:139-175.

lwata K, Kenshalo DR, Dubner R, Nahin RL (1992) Diencephalic projections from the superficial and deep laminae of the medullary dorsal horn in the rat. J Comp Neurol 321:404-420.

Jarrell TW, Gentile CG, McCabe PM, Schneiderman N (1986) The role of the medial geniculate region in differential Pavlovian conditioning of bradycardia in rabbits. Brain Res 374:126-136.

Jones EG, Burton H (1974) Cytoarchitecture and somatic sensory connectivity of thalamic nuclei other than the ventrobasal complex in the cat. J Comp Neurol 154:395-432.

Kudo M, Niimi K (1980a) Ascending projections of the inferior colliculus onto the medial geniculate body in the cat studied by anterograde and retrograde tracing tecluiques. Brain Res 155:113-117.

Kudo M, Niimi K (1980b) Ascending projections of the inferior colliculus in the cat: an autoradiographic study. J Comp Neurol 191:545-556. 
LeDoux JE, Farb C, Ruggiero DA (1990) Topographic organization of neurons in the acoustic thalamus that project to the amygdala. J Neurosci 10:1043-1054.

LeDoux JE, Iwata J, Pearl D, Reis DJ (1986) Disruption of auditory but not visual learning by destruction of intrinsic neurons in the medial geniculate body of the rat. Brain Res 371:395-399.

LeDoux JE, Ruggiero DA, Forest R, Stornetta R, Reis DJ (1987) Topographic organization of convergent projections to the thalamus from the inferior colliculus and spinal cord in the rat. $\mathbf{J}$ Comp Neurol 264:123-146.

Lenartz RC, Weinberger NM (1992) Analysis of response systems in Pavlovian conditioning reveals rapidly versus slowly acquired conditioned responses: support for two factors, implications for behavior and neurobiology. Psychobiology 20:93-119.

Love JA, Scott JW (1969) Some response characteristics of cells of the magnocellular division of the medial geniculate body of the cat. Can J Physiol Pharmacol 47:881-888.

Lund RD, Webster KE (1967) Thalamic afferents from the spinal cord and trigeminal nuclei. J Comp Neurol 130:313-328.

Martin GF (1969) Efferent tectal pathways of the opossum (Didelphis virginiana). J Comp Neurol 135:209-224.

McCabe PM, McEchron MD, Green EJ, Schneiderman N (1993) Effects of electrolytic and ibotenic acid lesions of the medial nucleus of the medial geniculate nucleus on single tone heart rate conditioning. Brain Res 619:291-298.

McCormick DA, 'I hompson RF (1984) Neuronal responses of the rabbit cerebellum during acquisition and performance of a classically conditioned nictitating membrane-eyelid response. J Neurosci 4:2811-2822.

McEchron MD, McCabe PM, Green EJ, Llabre MM, Schneiderman N (1995) Simultaneous single unit recording in the medial nucleus of the medial geniculate and amygdaloid central nucleus throughout habituation, acquisition, and extinction of the rabbit's classically conditioned heart rate. Brain Res 682:157-166.
McNaughton BL, O'Keefe J, Barnes CA (1983) The stereotrode: a new technique for simultaneous isolation of several single units in the central nervous system from multiple unit records. J Neurosci Methods 8:391-397.

Moore RY, Goldberg JM (1963) Ascending projections of the inferior colliculus in the cat. J Comp Neurol 121:109-136.

Moore RY, Goldberg JM (1966) Projections of the inferior colliculus in the monkey. Exp Neurol 14:429-438.

Mulkey RM, Malenka RC (1992) Mechanisms underlying induction of homosynaptic long-term depression in area CA1 of the hippocampus. Neuron 9:967-975.

Peschanski M (1984) Trigeminal afferents to the diencephalon in the rat. Neuroscience 12:465-487.

Powell EW, Hatton JB (1969) Projections of the inferior colliculus in cat J Comp Neurol 136:183-192.

Ring G, Ganchrow D (1983) Projections of the nucleus caudalis and spinal cord to brainstem and diencephalon in the hedgehog (Erinaceus europaeus and Paraechinus aethiopicus): a degeneration study. J Comp Neurol 216:132-151.

Supple WF, Kapp BS (1989) Response characteristics of neurons in the medial component of the medial geniculate nucleus during Pavlovian differential fear conditioning in rabbits. Behav Neurosci 103:1276-1286.

Tarlov EC, Moore RY (1966) The tecto-thalamic connections in the brain of the rabbit. J Comp Neurol 126:403-422.

Weinberger NM, Ashe JH, Metherate R, McKenna TM, Diamond DM, Bakin J (1990) Retuning auditory cortex by learning: a preliminary model of receptive field plasticity. Concepts Neurosci 1:91-132.

Weinberger NM, Javid R, Lepan B (1995) Heterosynaptic long-term facilitation of sensory-evoked responses in the auditory cortex by stimulation of the magnocellular medial geniculate in guinea pigs. Behav Neurosci 109:10-17. 